\title{
BMJ Open Cohort profile: Examining Neighbourhood Activities in Built Living Environments in London: the ENABLE London-Olympic Park cohort
}

Bina Ram, ${ }^{1}$ Claire M Nightingale, ${ }^{1}$ Mohammed T Hudda, ${ }^{1}$ Venediktos V Kapetanakis, ${ }^{1}$ Anne Ellaway, ${ }^{2}$ Ashley R Cooper, ${ }^{3,4}$ Angie Page, ${ }^{3}$ Daniel Lewis, ${ }^{5}$ Steven Cummins, ${ }^{5}$ Billie Giles-Corti, ${ }^{6}$ Peter H Whincup, ${ }^{1}$ Derek G Cook, ${ }^{1}$ Alicja R Rudnicka, ${ }^{1}$ Christopher G Owen ${ }^{1}$

To cite: Ram B, Nightingale CM, Hudda MT, et al. Cohort profile: Examining Neighbourhood Activities in Built Living Environments in London: the ENABLE London-Olympic Park cohort. BMJ Open 2016;6:e012643.

doi:10.1136/bmjopen-2016012643

- Prepublication history for this paper is available online. To view these files please visit the journal online (http://dx.doi.org/10.1136/ bmjopen-2016-012643).

Received 13 May 2016 Revised 19 August 2016 Accepted 30 September 2016

CrossMark

For numbered affiliations see end of article.

Correspondence to Professor Christopher G Owen; cowen@sgul.ac.uk

\section{ABSTRACT}

Purpose: The Examining Neighbourhood Activities in Built Living Environments in London (ENABLE London) project is a natural experiment which aims to establish whether physical activity and other health behaviours show sustained changes among individuals and families relocating to East Village (formerly the London 2012 Olympics Athletes' Village), when compared with a control population living outside East Village throughout.

Participants: Between January 2013 and December 2015, 1497 individuals from 1006 households were recruited and assessed (at baseline) (including 392 households seeking social housing, 421 seeking intermediate and 193 seeking market rent homes). The 2-year follow-up rate is $62 \%$ of households to date, of which $57 \%$ have moved to East Village.

Findings to date: Assessments of physical activity (measured objectively using accelerometers) combined with Global Positioning System technology and Geographic Information System mapping of the local area are being used to characterise physical activity patterns and location among study participants and assess the attributes of the environments to which they are exposed. Assessments of body composition, based on weight, height and bioelectrical impedance, have been made and detailed participant questionnaires provide information on socioeconomic position, general health/health status, well-being, anxiety, depression, attitudes to leisure time activities and other personal, social and environmental influences on physical activity, including the use of recreational space and facilities in their residential neighbourhood.

Future plans: The main analyses will examine the changes in physical activity, health and well-being observed in the East Village group compared with controls and the influence of specific elements of the built environment on observed changes. The ENABLE London project exploits a unique opportunity to evaluate a 'natural experiment', provided by the building and rapid occupation of East Village. Findings from the study will be generalisable to other

\section{Strengths and limitations of this study}

- The ENABLE London project is a controlled cohort study, evaluating a natural experiment to examine the effect of moving into social, intermediate and market rent accommodation in East Village (formerly the London 2012 Athletes' Village), on physical activity, health and wellbeing indicators.

- In total, 1497 participants (1278 adults and 219 children) from 1006 households located in Newham and Greater London have been recruited.

- Two-year follow-up of those in social housing is largely complete with $62 \%$ participation and where $57 \%$ have moved to East Village. Follow-up of those seeking intermediate and market-rent accommodation will continue to December 2017.

- The data set includes demographic, lifestyle, health and well-being indicators, measures of anthropometry (including bioimpedance), objective measures of physical activity combined with individual Geographical Positioning System data, and Geographical Information System-determined environmental measures of the local area.

- East Village provides family-sized accommodation. While the study is well powered to detect change in physical activity associated with moving to East Village in adults, too few children moved in to establish change in younger participants.

urban residential housing developments, and will help inform future evidence-based urban planning.

\section{INTRODUCTION}

Low physical activity is widespread and poses a serious public health challenge in the UK 
and worldwide. ${ }^{1}$ The need to increase population levels of physical activity is recognised in current health policy recommendations. ${ }^{2}{ }^{3}$ However, interventions to increase physical activity levels, particularly community-wide interventions, have shown limited effects, which are poorly maintained in the longer term. ${ }^{4} 5$ There has been increasing interest in whether the built environment, especially in urban settings, might be a key constraint that limits opportunities for physical activity. ${ }^{6}$ However, there is very limited high-quality experimental evidence examining the influence of change in the built environment on physical activity. ${ }^{6}{ }^{7}$ The ENABLE London project has been established to address this issue, by providing evidence from the investigation of a natural experiment examining whether changing the built environment can increase physical activity levels, as well as indicators of physical and mental health, in the general population. This question has important public health relevance, as small shifts in population levels of physical activity, in addition to other markers of health and wellbeing, appear to have an appreciable impact on health-related outcomes. ${ }^{8}$

The ENABLE London study takes advantage of the natural experiment provided by the rapid change of brown-field land in the London Borough of Newham, to create a novel built environment for public use and occupancy (namely 'East Village' E20, formerly the London 2012 Olympic Games Athletes' Village). East Village is a planned mixed-use residential neighbourhood development, incorporating commercial, retail, educational and transportation resources, with 1439 housing units for market rent, 704 intermediate units and 675 households for social rent. Specific activity permissive features designed to encourage physical activity include improving access to open land and parkland, unrivalled transport links, and active travel options (including extensive walking and cycling paths), design features of the local environment (such as street furniture, provision and arrangement of pedestrianised space, public space aesthetics, secure bicycle parking) and the provision of new formal cycling and walking facilities in the Queen Elizabeth Olympic Park such as the VeloPark, and cycle paths which extend into the Lee Valley and connect to the London Cycle Network. ${ }^{9}{ }^{10} \mathrm{~A}$ local school, Chobham Academy, is within walking distance and provides schooling for all 3-19 years. Retail outlets were planned within easy walking distance for everyday use (creating plazas at ground level within dedicated areas of East Village).${ }^{9}{ }^{10}$ Moreover, East Village is within the close proximity of Westfield Stratford CityEurope's largest urban shopping centre. Restriction of resident car parking (where less than a sixth of homes have a designated parking space) combined with improved public transport links is designed to encourage local residents to adopt active modes of transport. ${ }^{9} 10$

ENABLE London participants moving to East Village will be directly exposed to the new social and built environment, and its active design features, in the follow-up phase of the study. Participants who were seeking to move to East Village but remain in their place of origin (largely in East London) or move elsewhere will act as controls. The inclusion of occupants of social, intermediate and market rent accommodation will allow the study to examine the effects of the East Village environment on individuals from widely differing social origins, and to establish whether the effects differ by socioeconomic group.

The study evaluates a natural experiment, based on the provision of high-quality homes located in a neighbourhood specifically designed to encourage healthy, active living for people in the social, intermediate and market rent sectors. ENABLE London is one of a handful of studies of its type, ${ }^{11-13}$ the findings from which could help to inform future urban residential housing developments. While the East Village development is unique in origin, scale and spread, its impact should be generalisable to other major inner city conurbations, given the replication of this type of high-density housing in other settings. This is important given global calls to create more compact higher density cities. ${ }^{14}$

\section{COHORT DESCRIPTION \\ Participants}

The baseline population for this cohort were individuals and families who were seeking or applied for either social, intermediate or market rent accommodation in East Village. Most lived in East London, particularly the London Borough of Newham. Recruitment and baseline data collection were carried out between 1 January 2013 and 31 December 2015, before participants moved to East Village. In total, 1497 individuals (1278 adults, 219 children) were recruited from 1006 households. East Village did not attract as many families as anticipated, which explains the limited number of children recruited to participate in the study. Hence, only adults are considered further.

\section{Recruitment}

There were three distinct phases of recruitment for the different housing sectors: 392 households from the social sector were initially recruited between January 2013 and May 2014, 421 households seeking intermediate accommodation between July 2013 and November 2014 and 193 seeking market rent accommodation between September 2014 and December 2015; lower numbers recruited within the market rent sector reflected limitations on the extent and duration of access to applicants for accommodation. Recruitment processes for those in social housing were slightly different compared with other housing sectors. The East Thames Group was primarily responsible for recruiting participants in social housing, whereas the ENABLE London team (in association with Triathlon Homes and Get Living London) recruited participants from the other housing sectors. A flow diagram (figure 1) 


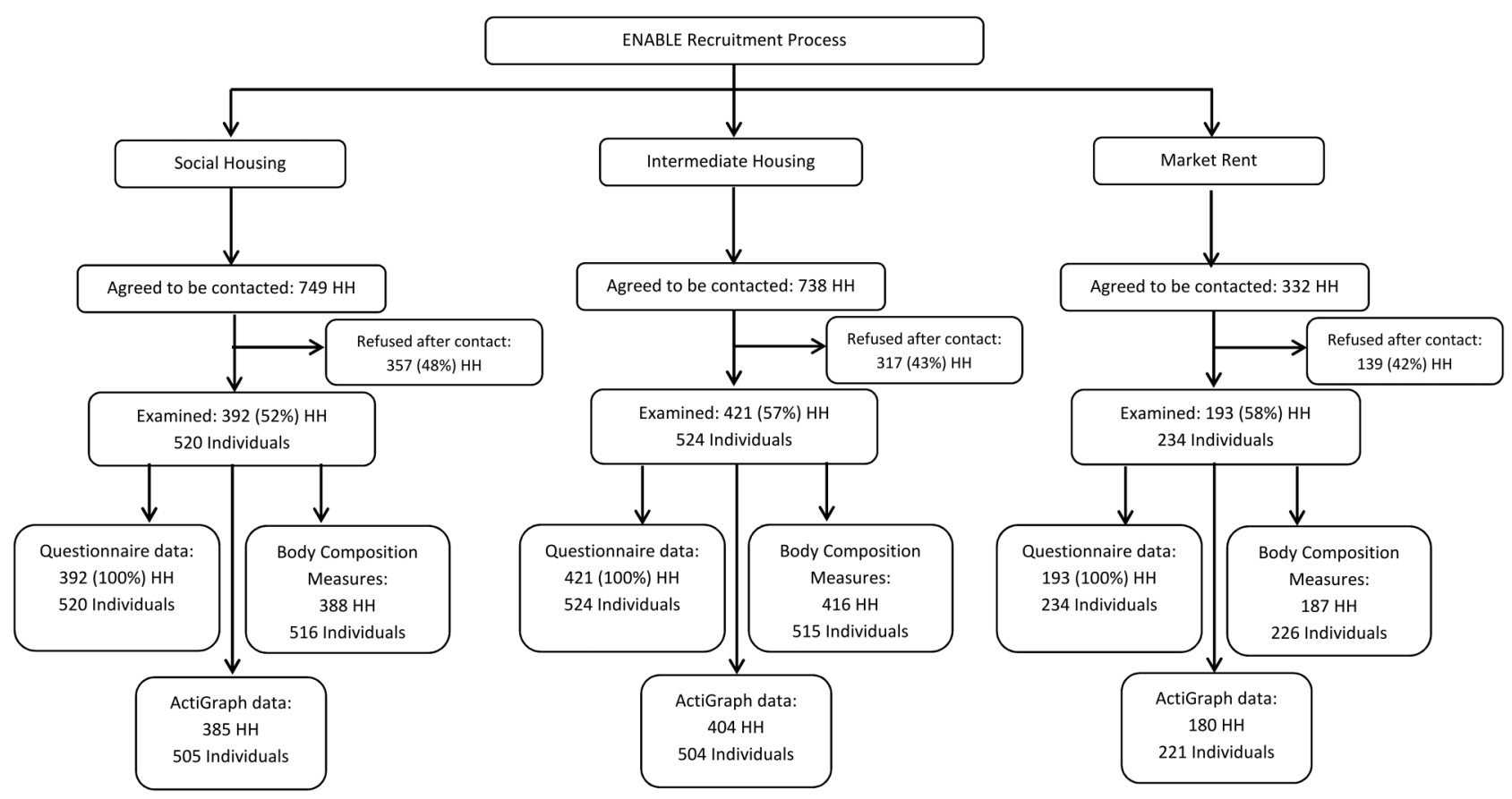

Figure 1 Flow diagram of adult participation by housing sector.

summarises recruitment and participation by housing sector. Of those who agreed to be contacted, participation rates were just over half in the social sector $(52 \%)$, but higher in those seeking intermediate and market rent accommodation $(57 \%, 58 \%$, respectively).

\section{Data collection}

Baseline and 2-year follow-up of study participants are being carried out at the participants' home (or at location convenient to the participant). Data items collected in the ENABLE London study at baseline and follow-up are listed in box 1 and summarised below.

\section{Physical activity level/pattern and location}

Objectively measured physical activity was the primary outcome, and was assessed over 7 days using hip-mounted ActiGraph GT3X+accelerometers, combined with assessment of physical activity location using Geographical Positioning System (GPS) travel recorders (Qstarz BT-1000XT). Accelerometers provided daily measures of steps, light and moderate to vigorous physical activity (MVPA-both overall and in $10 \mathrm{~min}$ bouts, in accordance with UK physical activity recommendations). ${ }^{3}$ Simultaneous use of ActiGraph accelerometers and GPS Travel recorders allows walking components of physical activity, as well as indoor and outdoor activities, to be identified, using methods previously described by the investigators. ${ }^{15}{ }^{16} \mathrm{In}$ addition, GPS data allow the geographical location at which different levels of physical activity occurs (from sedentary to vigorous, using established cut-offs in accelerometer data), at baseline and follow-up, to be identified. Together, these measures allow accelerometry data to be interpreted in depth, allowing the nature and location of recorded activities, particularly active forms of transport, such as walking and cycling, to be identified. Moreover, it allows the contribution of active transport local to place of residence to be quantified and compared between those living in East Village and control areas.

\section{Environmental exposures}

A Geographical Information System (GIS) was used to extract objective data on features of the local environment. In combination with ActiGraph and GPS data from study participants, this has allowed the location of where different levels of physical activity have been carried out (including high and low levels of activity), to be accurately identified. This method has been previously used by the investigators to establish the important contribution of walking to school and location (including land use type) to MVPA levels in children. ${ }^{16}{ }^{17} \mathrm{In}$ the present study, a number of data sources are being used to identify environmental and activity permissive features within East Village and control areas, including Ordnance Survey (OS) MasterMap, Integrated Transport Network (ITN) and Transport for London (TfL) sources, Olympic Delivery Authority and Local Authority data as well as other printed an online resources. In particular, OS data are being used to derive indices, such as land-use mix, street connectivity, residential density, walkability and connectivity indices, including walking distance to particular features of the built environment, including green space. $^{18}$

\section{Anthropometric measurements}

Height was measured to the last complete millimetre with a portable stadiometer at baseline and follow-up 
Box 1 Summary of data items collected at baseline and 2-year follow-up of the ENABLE London study

Physical activity and location data

- ActiGraph GT3X+accelerometer worn for 1 week (ActiGraph LLC, Florida, USA)

- QStarz BT-100XT GPS travel recorder worn for 1 week (QStarz International Co, Taiwan)

- GIS Ordinance Survey mapping of place of residence at baseline and 2-year follow-up to provide measures of land-use mix, street connectivity, residential density, walkability and connectivity indices

Anthropometry

- Height measured to the last complete millimetre (Leicester Stadiometer, Seca, Birmingham, UK).

- Weight measured to the last complete $0.1 \mathrm{~kg}$ using an electronic digital scale, and fat mass (kg), fat free mass (kg), muscle mass (kg) measured by leg-to-leg bioimpedance (Tanita SC-240 Body Composition Analyzer, Tanita, Tokyo, Japan)

BMI calculated as weight/height squared in $\mathrm{kg} / \mathrm{m}^{2}$

Questionnaire data

Demographics including date of birth, gender and ethnicity of participant

- Number of people living in the household, relationships, type of accommodation, household features (including lifts, stairs, garden), type of tenure, duration at current property, vehicles owned and dog ownership

- Qualifications, employment status and job title of adult participants (based on Census 2011 questions)

- Method of travel to work/place of study and daily commuting times

- Household income either as weekly or monthly amounts (based on National Evaluation of Sure Start income questions)

- Perception of general health, self-report of health problems (based on Census 2011 questions) and effects on mobility

- Health outcomes including assessments of mobility, self-care, usual activities, pain/discomfort, anxiety/depression and overall perception of health on a scale from 0 to 100 (using EuroQol EQ-5D questions)

- Satisfaction scores including perception of overall levels of satisfaction, feeling happy and anxious on a scale from 0 to 10 (based on questions used in the Integrated Household Survey 2011), and further assessment of anxiety and depression based on the Hospital Anxiety and Depression Scale

- Current and previous smoking status, and current alcohol consumption (using Health Survey for England questions)

- Perceptions of the local area/neighbourhood, including transport, leisure activities, vandalism, litter, traffic, attractiveness and safety, as well as assessment of social participation, support, cohesion and trust

- Type of activities carried out and frequency of carrying out vigorous, moderate, walking, sitting activities in the last 7 days (based on the IPAQ short questionnaire)

- Cost of activities including membership fees, vouchers received, equipment bought to do physical activity

- Attitudes to exercise

- TV and computers/screen time assessment

Eating and sleeping

(Leicester Stadiometer, Seca, Birmingham, UK). Weight and leg-to-leg bioimpedance were assessed using an electronic Tanita SC-240 body composition analyser (Tanita, Tokyo, Japan) to provide measures of fat mass $(\mathrm{kg})$ and fat free mass $(\mathrm{kg})$; body mass index (BMI) was calculated as weight $/$ height $^{2}\left(\mathrm{~kg} / \mathrm{m}^{2}\right)$. In total, eight Leicester stadiometers and Tanita SC-240 body composition analysers were used to measure participants. The Tanita devices were operated using factory default settings and were regularly checked in accordance with recommended review procedures.

\section{Questionnaire data}

Questionnaires were converted into electronic format using SNAP Surveys software (V.11, SNAP Surveys, London, UK), and completed by study participants using dedicated laptops. Questionnaires used established validated methodologies to collect detailed information on patterns and types of activity local to place of residence. In particular, the 'Neighbourhood Physical Activity Questionnaire' provides data to examine walking within the neighbourhood, ${ }^{19}$ and the 'Neighbourhood Environment Walking Scale' (NEWS) perceptions of the neighbourhood environment. ${ }^{2021}$ Information on self- defined ethnic origin (based on the Census, 2011) and a range of social markers were recorded (including employment status, income, duration and location of work), together with home address and postcode of residence, allowing GIS-determined distance to local amenities to be measured. Questions about general health/ health status, ${ }^{22}$ well-being, anxiety and depression, including clinical and subclinical forms of assessment suitable for use in community settings, have also been used. ${ }^{23-26}$ Physical activity was assessed using an adaptation of the short-form, self-reported International Physical Activity Questionnaire (IPAQ), ${ }^{27}$ to provide perceived levels of physical activity in addition to objective measures. Adults are asked about attitudes to physical activities (including sedentary, such as screentime, and physically active forms) and factors which influence their physical activity behaviour. Participants are asked about perceived personal, social and environmental influences on physical activity, their use of recreational space (particularly walkways and cycle paths) and facilities in their residential neighbourhood (including costs incurred). Participants are also asked about the availability, accessibility (method of travel and journey times) and usage of local amenities 
(walkways, cycle paths, parks, swimming pools, etc); their perceptions of the safety of these amenities and the degree to which they permit their child independent or supervised use. The questionnaire also includes sections to ascertain levels of social participation, support, cohesion and trust. ${ }^{28}$ These items are particularly relevant to gauge how use and perceptions of the local area by others impact on individual use and how this might differ from objectively measured features of their neighbourhood.

\section{Qualitative data}

In addition to the rich quantitative data, focus groups among study participants who have and have not moved to East Village have been carried out to identify issues of importance, particularly about perceptions and use of their local environment. GIS and GPS data are also being combined with qualitative spatial narratives among study participants. These narratives use individual participant maps of travel patterns to provide context of use, that is, reasons and purpose of travel and to tailor interviews to investigate how the built environment has influenced individual patterns of behaviour.

Ethical approval: The study was approved by the City Road and Hampstead Ethical Review Board (REC reference number 12LO1031); all participants gave written, informed consent.

\section{Characteristics of study participants}

Table 1 summarises baseline characteristics of adult participants by housing sector; the small number of children were recruited from the social sector and have not been included further. Participants from social housing were older, had a higher number of participants per household, with greater representation of females $(73 \%)$ and those of Black and Asian ethnic origin. Participants seeking intermediate and market-rent housing were younger, more equally gender balanced (48\%, $44 \%$ female, respectively), and had higher representation of whites compared with other ethnic groups. The proportion of those reporting poorer general health was higher among those in social housing, compared with other housing sectors (table 1). Moreover, the percentage reporting medium to high levels of satisfaction with life was higher among those seeking market rent $(81 \%)$ and intermediate $(78 \%)$ accommodation, compared with those in the social sector $(68 \%$-table 1$)$. Two-year follow-up of those in the social sector began in January 2015 and is now largely complete; follow-up of those seeking intermediate or market rent accommodation will continue to December 2017.

\section{FINDINGS TO DATE}

The ENABLE London study has recruited participants from different housing sectors (table 1). Baseline data have previously shown that those in social housing were less likely to report enjoying living and walking in their local neighbourhood, that their local area is attractive to look at and that they have good local transport and leisure services. ${ }^{29}$ They were also more likely to report problems with vandalism and litter in their local area, as well as having greater concerns over crime and safety, compared with the other housing types. ${ }^{29}$ Too much traffic was reported as a problem across all housing sectors. ${ }^{29}$ Two focus groups among those in the social housing sector have been completed to date; one in a group who have moved to East Village and another in those who have not moved to East Village (7-9 participants in each). Among those who had moved, East Village was recognised as a safe, clean, spacious environment, with good local facilities, including public transport, which encouraged walking activities. However, the cost of living was high, with few shops, particularly super markets, serving their income range, making it more difficult to save. The cost of living was also reported as a problem among the non-movers, which limited opportunities for physical activity in the local area. These themes will be explored in further focus group among study participants in other housing sectors.

Compliance with wearing the ActiGraph physical activity monitor, defined as 9 hours wear for at least 4 days, was good with nearly two-thirds recording adequate wear $(66 \%)$ in social households, $84 \%$ and $89 \%$ among those seeking intermediate and market rent housing, respectively. Objective measures of physical activity showed lower levels of activity among those in social housing, with fewer daily steps, and less time spent in higher levels of activity (table 2). Time spent in $10 \mathrm{~min}$ bouts of MVPA (equivalent to just over $100 \mathrm{~min} /$ week) were well below current recommendations of $150 \mathrm{~min} /$ week in all sectors, and markedly lower among those in social housing. ${ }^{3}$ How these objective measures of physical activity relate to GIS-derived measures of walkability will be an early focus of our work, ${ }^{30}$ allowing validation of a walkability index developed in an American setting, to be objectively validated within a European context, by combining GIS, GPS and ActiGraph data recorded at an individual level. ${ }^{18}$ The need to further understand the relationship between the physical environment and activity within European settings has recently been highlighted. ${ }^{31}$ In addition, measures of anthropometry suggest higher levels of adiposity, including measures of BMI, obesity (defined as $\geq 30 \mathrm{~kg} / \mathrm{m}^{2}$ ), fat mass and fat mass-derived levels of obesity (defined as $\geq 30 \%$ body fat in women, and $\geq 25 \%$ body fat in men), ${ }^{32}$ among adults in the social sector compared with other housing sectors, with similar levels among those seeking intermediate and market rent accommodation (table 2). However, the influence of age, gender and ethnicity on these differences is yet to be determined.

Two-year follow-up of the cohort will provide the opportunity to examine whether indicators of health and well-being, perceptions of the local living environment and objective measures of physical activity and adiposity change on moving to East Village, compared 
Table 1 Baseline demographic, self-reported health status and local environment perceptions of ENABLE London adult participants, by housing sector

\begin{tabular}{|c|c|c|c|c|}
\hline & Social housing & $\begin{array}{l}\text { Seeking } \\
\text { intermediate housing }\end{array}$ & $\begin{array}{l}\text { Seeking market } \\
\text { rent housing }\end{array}$ & All participants \\
\hline Number of adults & 520 & 524 & 234 & 1278 \\
\hline Number of adults/household & 1.3 & 1.2 & 1.2 & 1.3 \\
\hline Median age (IQR) & $36.6(27.3,44.2)$ & $29.8(26.0,34.8)$ & $27.7(24.4,33.1)$ & $31.1(25.7,39.5)$ \\
\hline \multirow[t]{2}{*}{ Female (\%) } & $379(72.9)$ & 249 & 103 & 731 \\
\hline & & 47.5 & 44.0 & 57.2 \\
\hline \multicolumn{5}{|l|}{ Ethnicity (\%) } \\
\hline White & $96(18.5)$ & $358(68.3)$ & $163(69.7)$ & $617(48.3)$ \\
\hline Black & $251(48.3)$ & $55(10.5)$ & $17(7.3)$ & $323(25.3)$ \\
\hline Asian & $108(20.8)$ & 77 (14.7) & $29(12.4)$ & $214(16.7)$ \\
\hline Other & $65(12.5)$ & $34(6.5)$ & $25(10.7)$ & $124(9.7)$ \\
\hline \multicolumn{5}{|l|}{ Employment status (\%)* } \\
\hline Employed & $252(48.8)$ & 492 (93.9) & 204 (87.2) & $948(74.4)$ \\
\hline Economically inactive & 264 (51.2) & $32(6.1)$ & $30(12.8)$ & $326(25.6)$ \\
\hline \multicolumn{5}{|l|}{ NS-SEC (Employed only) (\%) } \\
\hline $\begin{array}{l}\text { Higher managerial, administrative and } \\
\text { professional }\end{array}$ & $61(24.2)$ & $375(76.2)$ & $155(76.0)$ & $591(62.3)$ \\
\hline Intermediate occupations & $62(24.6)$ & $79(16.1)$ & $38(18.6)$ & $179(49.0)$ \\
\hline Routine and manual occupations & $125(49.6)$ & $34(6.9)$ & $11(5.4)$ & $170(24.2)$ \\
\hline Unclassified & $4(1.6)$ & $4(0.8)$ & $0(0.0)$ & $8(4.5)$ \\
\hline \multicolumn{5}{|l|}{ General health status (Census) (\%) } \\
\hline Very good & $140(26.9)$ & $153(29.2)$ & $72(30.8)$ & $365(28.6)$ \\
\hline Good & $253(48.7)$ & $310(59.2)$ & $140(59.8)$ & $703(55.0)$ \\
\hline Fair & 103 (19.8) & $58(11.1)$ & $18(7.7)$ & $179(14.0)$ \\
\hline Bad & $19(3.7)$ & $2(0.4)$ & $4(1.7)$ & $25(2.0)$ \\
\hline Very bad & $5(1.0)$ & $1(0.2)$ & $0(0.0)$ & $6(0.5)$ \\
\hline \multicolumn{5}{|l|}{ HADS-anxiety (\%)† } \\
\hline Normal & $332(65.2)$ & $369(71.0)$ & $148(64.1)$ & $849(67.4)$ \\
\hline Borderline & $97(19.1)$ & $94(18.1)$ & $60(26.0)$ & 251 (19.9) \\
\hline Abnormal & $80(15.7)$ & $57(11.0)$ & $23(10.0)$ & $160(12.7)$ \\
\hline \multicolumn{5}{|l|}{ HADS-depression (\%)‡ } \\
\hline Normal & $316(65.3)$ & $413(81.0)$ & $194(85.5)$ & $923(75.6)$ \\
\hline Borderline & $110(22.7)$ & $76(14.9)$ & $27(11.9)$ & $213(17.4)$ \\
\hline Abnormal & $58(12.0)$ & $21(4.1)$ & $6(2.6)$ & $85(7.0)$ \\
\hline \multicolumn{5}{|l|}{ Satisfaction with life (\%)§ } \\
\hline Very low & $51(10)$ & $22(4)$ & $10(4)$ & $83(7)$ \\
\hline Low & $118(23)$ & $95(18)$ & $34(15)$ & $247(19)$ \\
\hline Medium & $185(36)$ & $308(59)$ & $156(67)$ & $649(51)$ \\
\hline High & $164(32)$ & 98 (19) & $33(14)$ & $295(23)$ \\
\hline \multicolumn{5}{|c|}{ Local perceptions-enjoy living in the local area (\%) } \\
\hline Strongly agree & $83(16.0)$ & $149(28.4)$ & $57(24.4)$ & $289(22.6)$ \\
\hline Agree & $192(36.9)$ & $212(40.5)$ & $110(47.0)$ & $514(40.2)$ \\
\hline Neither & $111(21.3)$ & $89(17.0)$ & $45(19.2)$ & $245(19.2)$ \\
\hline Disagree & $78(15.0)$ & $62(11.8)$ & $16(6.8)$ & $156(12.2)$ \\
\hline Strongly disagree & $56(10.8)$ & $12(2.3)$ & $6(2.6)$ & $74(5.8)$ \\
\hline \multicolumn{5}{|c|}{$\begin{array}{l}{ }^{*} \text { Four missing responses. } \\
\text { †Eighteen missing responses. } \\
\text { †Fifty-seven missing responses. } \\
\text { §Four missing responses. } \\
\text { HADS, Hospital Anxiety and Depression Scale; NS-SEC, National Statistics Socioeconomic Classification. }\end{array}$} \\
\hline
\end{tabular}

with change observed among those who do not move to East Village. All analyses will allow for the hierarchical nature of the data, using multilevel models to take appropriate account of factors operating within subject, as well as at individual and household level in East Village and control areas. Models will be extended to examine whether any differences between the intervention and control areas are modified by age group, gender, ethnic group, social class, housing sector, proximity and accessibility to certain facilities. The extent to which changes in physical activity in those living in the Village can be directly attributed to the use of local 
Table 2 Baseline objective measures of physical activity and anthropometry of ENABLE London adult participants, by housing sector

\begin{tabular}{|c|c|c|c|c|}
\hline & Social housing & $\begin{array}{l}\text { Seeking } \\
\text { intermediate } \\
\text { housing }\end{array}$ & $\begin{array}{l}\text { Seeking market } \\
\text { rent housing }\end{array}$ & All participants \\
\hline Daily physical activity & 505 & 504 & 221 & 1230 \\
\hline Compliance* & $66 \%$ & $84 \%$ & $89 \%$ & $78 \%$ \\
\hline Number with compliant PA data & 336 & 421 & 197 & 954 \\
\hline Steps/day & 7803 (3303) & $9684(2924)$ & 9337 (2990) & 8950 (3190) \\
\hline Time in light activity (min/day) $\dagger$ & $175(140,212)$ & $128(101,157)$ & $117(90,156)$ & $139(106,180)$ \\
\hline Time in MVPA (min/day) & $50(26)$ & $65(23)$ & $65(25)$ & $60(26)$ \\
\hline $\begin{array}{l}\text { Time in } 10 \text { min bouts of MVPA } \\
\text { (min/day) } \dagger\end{array}$ & $7(1,15)$ & $21(10,34)$ & $21(12,36)$ & $15(6,30)$ \\
\hline Registered time (min/day) & $775(82)$ & $802(72)$ & $808(69)$ & $794(77)$ \\
\hline Anthropometry & 516 & 515 & 226 & 1257 \\
\hline Height $(\mathrm{m})$ & $1.65(0.09)$ & $1.71(0.10)$ & $1.72(0.10)$ & $1.69(0.10)$ \\
\hline Weight $(\mathrm{kg}) \dagger$ & $70.9(62.7,84.1)$ & $70.6(61.8,80.8)$ & $72.8(61.0,80.3)$ & $71.1(61.9,81.7)$ \\
\hline $\mathrm{BMI}\left(\mathrm{kg} / \mathrm{m}^{2}\right) \dagger$ & $26.3(23.4,30.5)$ & $23.9(21.9,26.7)$ & $23.8(21.5,25.8)$ & $24.7(22.2,27.8)$ \\
\hline Number obese based on BMI (\%)‡ & $138(26.7)$ & $50(9.7)$ & $13(5.8)$ & $201(16.0)$ \\
\hline Fat mass $(\mathrm{kg})+\emptyset$ & $22.8(15.6,31.2)$ & $15.4(11.1,21.4)$ & $14.8(10.8,19.9)$ & $17.7(12.6,25.5)$ \\
\hline Number obese based on fat mass (\%)§ף & $315(61.4)$ & $145(28.8)$ & $52(23.1)$ & $512(41.3)$ \\
\hline \multicolumn{5}{|c|}{$\begin{array}{l}\text { Mean and SD presented for normally distributed variables. } \\
\text { *Compliance defined as } 9 \text { hours/day for at least } 4 \text { days. } \\
\text { †Non-normally distributed variables presented as median and IQR (lower quartile to upper quartile). } \\
\ddagger \text { Obesity defined as } \mathrm{BMI} \geq 30 \mathrm{~kg} / \mathrm{m}^{2} \text {. } \\
\text { §Obesity defined as } \geq 30 \% \text { body fat in females, and } \geq 25 \% \text { body fat in males. } \\
\text { ๆSixteen missing responses. }\end{array}$} \\
\hline
\end{tabular}

facilities, and which facilities in particular, will be examined using data from questionnaire, GPS and GIS measures. Subsidiary objectives (such as change in weight and body fat) will be addressed using a similar analytical approach, but without the need to allow for replicates within participant; multilevel models will be extended to include binary as well as continuous outcomes. Time-dependent covariates that might affect absolute levels of physical activity such as weather should, by design, be balanced between the intervention and control area by examining study participants at similar times of year, but we will also explore linking Met Office weather data to directly control for weather. Further details of the analysis plan have been published. ${ }^{30}$ Follow-up of those in the social sector is largely complete, with $62 \%$ of the entire baseline cohort being seen to date; $57 \%$ have moved to East Village and $43 \%$ have not. Figure 2 shows the geographic home locations of study participants at baseline, which highlights the Newham focus among those in social housing, and greater London geographic diversity of participants seeking intermediate and market rent accommodation. Follow-up of the remaining cohort is likely to show a greater skew towards those who have moved to East Village, due to more focused marketing of intermediate and market rent accommodation. However, the study design is robust to some imbalance between the number of movers and non-movers.

Early priorities for the study will be to identify changes in physical activity and other health behaviours, well-being and perceptions of the environment between those that move and do not move to East Village, to understand their potential sociodemographic determinants and whether these differ across housing sectors. If change is observed, we will examine whether this can be attributed to specific features of the East Village built environment, identified objectively using GIS mapping and self-report measures of the area.

\section{STRENGTHS AND LIMITATIONS}

The building of East Village provided an important opportunity to evaluate a 'natural experiment' based on the major and focused change of an inner city urban built environment that has been specifically designed to encourage walking, cycling and healthy living. It is also unique because it involves residents from widely differing socioeconomic backgrounds. While many developments of this scale are underway or are being planned in cities globally, few have been (or are being) evaluated and most are less easily evaluated, given that the timescale of their development is much slower than in the case presented by East Village. The rapid occupancy of this development is a major strength, providing the opportunity for preassessment and postassessment, and to compare 2-year change in health outcomes among those who do and do not move to East Village. The different housing tenures within East Village also allow for the evaluation of socioeconomic position as an effect modifier, as the impact of the built environment may vary by socioeconomic position. The focus on increasing 

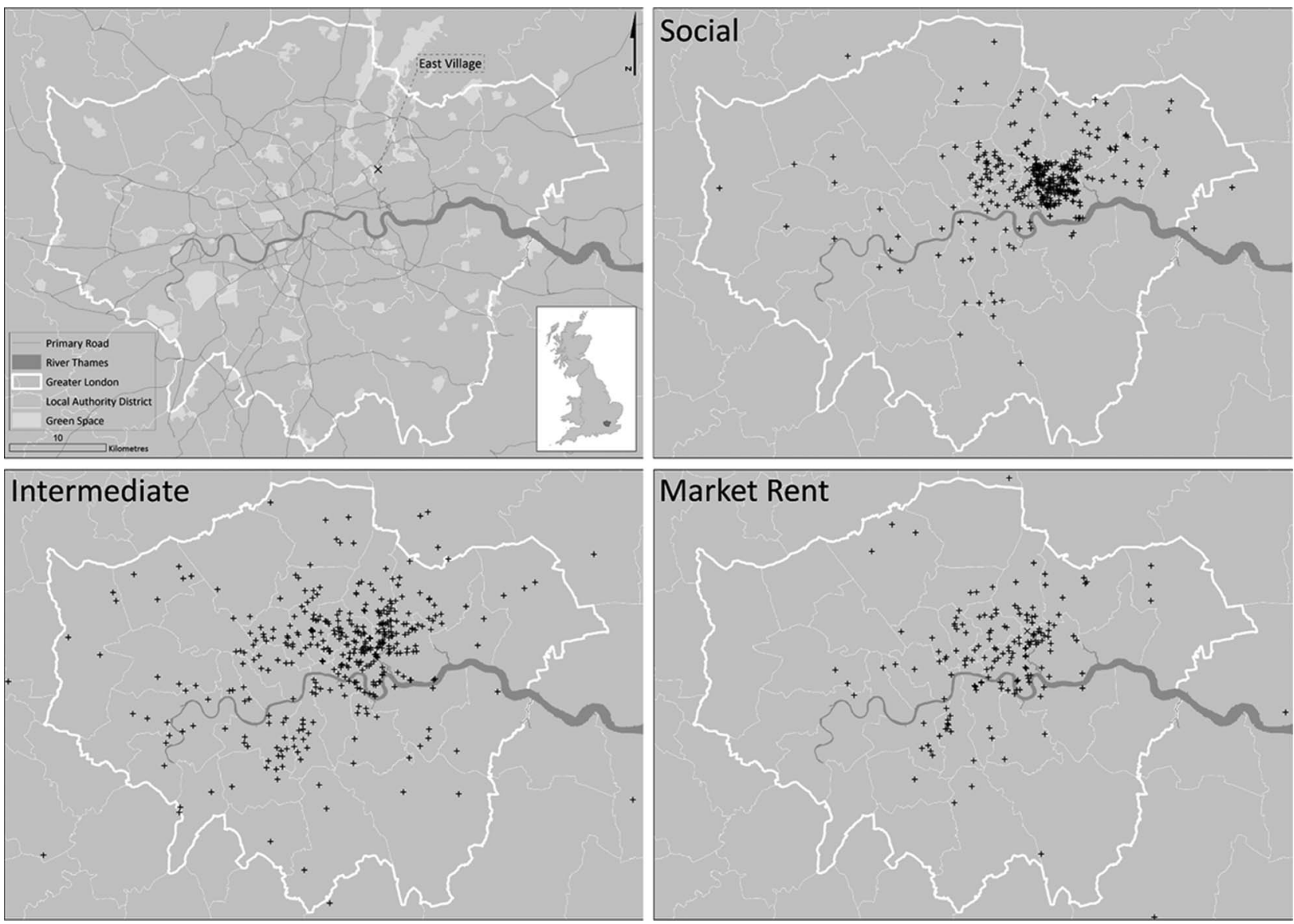

Figure 2 Baseline locations of social, intermediate and market rent households participating in the ENABLE London study.

levels of accessible and low-cost forms of physical activity will be particularly relevant to individuals and households of lower socioeconomic status and has the potential to inform efforts to reduce health inequalities. ${ }^{33}$ This will allow us to investigate whether the built environment can favourably influence higher levels of physical activity (particularly walking and cycling), as well as reducing time in sedentary activities, particularly among low-income groups with fewer opportunities for recreational activities. ${ }^{33}$ Moreover, the colocation of this diverse population of differing housing tenures to one community also constitutes a social experiment, providing opportunities for residents to observe and learn from the behaviour of others. ${ }^{34}$

The ENABLE London cohort was predicated on recruiting 1200 adults from 1200 households, and has succeeded in recruiting 1278 adults from 1006 homes. Given the modest imbalance between movers and nonmovers, the compliance and follow-up rate observed to date, the study is powered to detect a 750 step change $(0.3 \mathrm{SD})$ at $90 \%$ power and with a probability of 0.01 among those who move to East Village. The initial aim was to recruit similar numbers of adults and children (aged 8 or more years), especially as most of the accommodation in East Village is family-sized (ie, 2 bedrooms or more). Although this was partially achieved in the social sector (with 209 children, largely due to the allocation to families in need of rehousing), the baseline demographic of those seeking intermediate and market rent accommodation had an adult focus. This reflects the demography of those who have chosen to move to East Village, which is heavily skewed towards young professionals. This demographic profile was an unexpected outcome of the development, which was purposely designed for family occupancy. The study remains well powered to detect any potential change in adult physical activity.

In terms of the representativeness of the ENABLE London cohort, we have compared our physical activity data to a nationally representative study, Health Survey for England 2008, ${ }^{35}$ which used a similar methodology, that is, the same waist-worn accelerometer (ActiGraph), worn for an equivalent wear time (1 week). Adults aged 16-34 years from this study recorded $40 \mathrm{~min} /$ day in MVPA, of which $15 \mathrm{~min}$ was in $10 \mathrm{~min}$ bouts. Our baseline data suggest comparable levels of activity among those of a similar age in the social sector, with $47 \mathrm{~min}$ of daily MVPA, $7 \mathrm{~min}$ in bouts (with an IQR between 1 and $15 \mathrm{~min}$ ), but higher levels among those in the intermediate and market rent sectors with 65 min of MVPA and $>20$ min recorded in bouts. While this suggests differences in baseline physical activity levels across the 
housing sectors in the ENABLE London cohort, there was no evidence of a trend across other social markers (ie, income groups) in the Health Survey for England study. In terms of geographic patterns in physical activity, reanalysis of Health Survey for England (2012) data did not suggest that self-reported higher levels of physical activity in London were unduly higher or lower compared with other Government Office Regions. ${ }^{36}$

Specific features of the East Village development that could influence health and well-being (such as use of pathways, cycle paths, links to public transport, open spaces and leisure facilities) are (or could be) features of many built environment developments. The GIS measures will identify the availability of facilities, while the GPS will specifically allow the use of such facilities to be identified (including frequency of use, and time of day) and related to type of use (for leisure, work, etc) and objectively measured duration and intensity of physical activity associated with their use. Furthermore, questionnaire data combined with qualitative focus groups and spatial narratives will allow us to investigate how perception of the built environment influence travel patterns. Hence, findings from this study will have substantial potential for wider generalisability to other inner city major conurbations. An ultimate goal of the project is to identify evidence-based design features of the built environment that encourage physical activity and improve health behaviours. It is hoped that the identification of these environmental features will provide architects, urban designers and planners with evidence-based urban design elements, which are required for future developments.

\section{Author affiliations}

${ }^{1}$ Population Health Research Institute, St George's, University of London, Cranmer Terrace, London, UK

${ }^{2} \mathrm{MRC} / \mathrm{CSO}$ Social and Public Health Sciences Unit, University of Glasgow, Glasgow, UK

${ }^{3}$ Centre for Exercise, Nutrition and Health Sciences, University of Bristol, Bristol, UK

${ }^{4}$ Bristol Biomedical Research Unit in Nutrition, Diet and Lifestyle, National Institute for Health Research, Bristol, UK

${ }^{5}$ London School of Hygiene and Tropical Medicine, London, UK

${ }^{6}$ McCaughey VicHealth Community Wellbeing Unit, NHMRC Centre for Research Excellence in Healthy Liveable Communities, School of Population and Global Health, University of Melbourne, Melbourne, Victoria, Australia

Acknowledgements The authors thank the East Thames Group, Triathlon Homes and Get Living London who have assisted in recruiting participants into the ENABLE London study. The ENABLE London study is advised by a Steering Committee chaired by Professor Hazel Inskip (University of Southampton), with Dr David Ogilvie (University of Cambridge) and Professor Andy Jones (University of East Anglia) as academic advisors and Mrs Kate Worley (formerly East Thames Group Assistant Director for Strategic Housing) as the lay/stakeholder member. The authors are grateful to the members of the ENABLE London study team (in particular Asma Burale, Sarah Griffiths, Aine Hogan, Cathy McKay, Katrin Peuker, Nasiba Zafar) and to participating households, without whom this study would not be possible.

Contributors All authors read and contributed to this manuscript. CGO, ARR, $A E, A R C, A P, D L, S C, B G-C, D G C$ and PHW designed the study and raised funding. $B R, A R R$ and $C G O$ collected data for the study and enrolled participants. BR, CMN, MTH, VVK, ARR and CGO undertook data management. BR, CMN, MTH and ARR analysed the data. BR and CGO wrote the first draft of the report, to which all authors contributed. CGO is responsible for data integrity.

Funding This research is being supported by project grants from the Medical Research Council National Prevention Research Initiative (MR/J000345/1) and National Institute for Health Research (12/211/69). BR is supported by a St George's, University of London, Graduate School PhD studentship. Diabetes and obesity prevention research at St George's, University of London is supported by the National Institute for Health Research (NIHR) Collaboration for Leadership in Applied Health Research and Care (CLAHRC) South London. $\mathrm{AE}$ is funded by the UK Medical Research Council as part of the

Neighbourhoods and Communities Programme (MC_UU_12017-10). BG-C is supported by an NHMRC Principal Research Fellowship (\#1107672). ARC is supported by National Institute for Health Research (NIHR) Bristol Nutrition Biomedical Research Unit based at University Hospitals Bristol NHS Foundation Trust and the University of Bristol.

Disclaimer The views expressed are those of the author(s) and not necessarily those of the funding agencies, the NHS, the NIHR or the Department of Health.

Competing interests None declared.

Ethics approval NRES Committee London: City Road and Hampstead 12/LO/ 1031.

Provenance and peer review Not commissioned; externally peer reviewed.

Data sharing statement Further details of the ENABLE London study are available from the study website (http://www.enable.sgul.ac.uk/). The ongoing collection and management of data has been made possible through grant funding from the Medical Research Council and the National Institute of Health Research. We welcome proposals for collaborative projects. For general data sharing inquiries, contact CGO (cowen@sgul.ac.uk).

Open Access This is an Open Access article distributed in accordance with the terms of the Creative Commons Attribution (CC BY 4.0) license, which permits others to distribute, remix, adapt and build upon this work, for commercial use, provided the original work is properly cited. See: http:// creativecommons.org/licenses/by/4.0/

\section{REFERENCES}

1. Lim SS, Vos T, Flaxman AD, et al. A comparative risk assessment of burden of disease and injury attributable to 67 risk factors and risk factor clusters in 21 regions, 1990-2010: a systematic analysis for the Global Burden of Disease Study 2010. Lancet 2012;380:2224-60.

2. Department of Health. 2009 Annual Report of the Chief Medical Officer. 2009. http://www.sthc.co.uk/Documents/CMO_Report_2009. pdf (accessed Aug 2013).

3. Department of Health. Physical Activity, Health Improvement and Protection. Start active, stay active: a report on physical activity from the four home countries. Chief Medical Officers, 2011. https://www. gov.uk/government/uploads/system/uploads/attachment_data/file/ 216370/dh_128210.pdf (accessed online Jul 2016).

4. Baker PR, Francis DP, Soares J, et al. Community wide interventions for increasing physical activity. Cochrane Database Syst Rev 2015;1:CD008366.

5. Hillsdon M, Foster C, Thorogood M. Interventions for promoting physical activity. Cochrane Database Syst Rev 2005;(1):CD003180.

6. NICE public health guidance 8. Promoting and creating built or natural environments that encourage and support physical activity. 2008. http://www.nice.org.uk/guidance/ph8 (accessed Apr 2016).

7. Brownson RC, Hoehner CM, Day K, et al. Measuring the built environment for physical activity: state of the science. Am J Prev Med 2009;36(4 Suppl):S99-123.

8. Ekelund U, Ward HA, Norat T, et al. Physical activity and all-cause mortality across levels of overall and abdominal adiposity in European men and women: the European Prospective Investigation into Cancer and Nutrition Study (EPIC). Am J Clin Nutr 2015;101:613-21.

9. London Legacy Development Corporation. Your sustainability guide to Queen Elizabeth Olympic Park 2030. 2012. http:// queenelizabetholympicpark.co.uk/our-story/transforming-east-london/ sustainability (accessed Apr 2016). 
10. East Village London E20. About East Village London. 2016. http:// www.eastvillagelondon.co.uk/about-us (accessed Jun 2016).

11. Knuiman MW, Christian HE, Divitini ML, et al. A longitudinal analysis of the influence of the neighborhood built environment on walking for transportation: the RESIDE study. Am J Epidemiol 2014;180:453-61.

12. Giles-Corti B, Bull F, Knuiman M, et al. The influence of urban design on neighbourhood walking following residential relocation: Iongitudinal results from the RESIDE study. Soc Sci Med 2013;77:20-30.

13. Wells NM, Yang Y. Neighborhood design and walking. A quasiexperimental longitudinal study. Am J Prev Med 2008;34:313-19.

14. OECD Green Growth Studies. Compact City Policies: A comparative assessment. 2012. http://www.oecd.org/greengrowth/ compact-city-policies-9789264167865-en.htm (accessed Apr 2016).

15. Cooper AR, Page AS, Wheeler BW, et al. Mapping the walk to school using accelerometry combined with a global positioning system. Am J Prev Med 2010;38:178-83.

16. Southward EF, Page AS, Wheeler BW, et al. Contribution of the school journey to daily physical activity in children aged 11-12 years. Am J Prev Med 2012;43:201-4.

17. Lachowycz K, Jones AP, Page AS, et al. What can global positioning systems tell us about the contribution of different types of urban greenspace to children's physical activity? Health Place 2012;18:586-94.

18. Frank LD, Sallis JF, Saelens BE, et al. The development of a walkability index: application to the Neighborhood Quality of Life Study. Br J Sports Med 2010;44:924-33.

19. Giles-Corti B, Timperio A, Cutt $\mathrm{H}$, et al. Development of a reliable measure of walking within and outside the local neighborhood: RESIDE's Neighborhood Physical Activity Questionnaire. Prev Med 2006;42:455-9.

20. Saelens BE, Sallis JF, Black JB, et al. Neighborhood-based differences in physical activity: an environment scale evaluation. Am J Public Health 2003;93:1552-8.

21. Rosenberg D, Ding D, Sallis JF, et al. Neighborhood Environment Walkability Scale for Youth (NEWS-Y): reliability and relationship with physical activity. Prev Med 2009;49:213-18.

22. Office for National Statistics. 2011 Census. 2012. https://www.ons. gov.uk/census/2011census (accessed Apr 2016).

23. Office of National Statistics. Measuring what matters: National Statistician's reflections on the National Debate on Measuring National Well-being. 2011. http://webarchive.nationalarchives.gov.uk/ 20160105160709/http://www.ons.gov.uk/ons/guide-method/ user-guidance/well-being/about-the-programme/index.html (accessed Apr 2016).

24. Zigmond AS, Snaith RP. The hospital anxiety and depression scale. Acta Psychiatr Scand 1983;67:361-70.
25. Ellaway A, Macintyre S. Does housing tenure predict health in the UK because it exposes people to different levels of housing related hazards in the home or its surroundings? Health Place 1998;4:141-50.

26. Brooks R. EuroQol: the current state of play. Health Policy 1996;37:53-72.

27. Craig CL, Marshall AL, Sjöström M, et al. International physical activity questionnaire: 12 -country reliability and validity. Med Sci Sports Exerc 2003;35:1381-95.

28. Araya R, Dunstan F, Playle R, et al. Perceptions of social capital and the built environment and mental health. Soc Sci Med 2006;62:3072-83.

29. Owen CG, Ram B, Kapetanakis V, et al. Will moving into social and affordable housing in East Village, London, UK, increase family physical activity levels? Evaluation of a natural experiment. Lancet 2014;384(Suppl 2):S59.

30. Owen C, Cook DG, Cummins S, et al. PHR-12/211/69: does active design increase walking and cycling? Evaluation of a natural experiment examining whether moving into housing in East Village increases family levels of physical activity, particularly walking and cycling. 2014. http://www.nets.nihr.ac.uk/projects/phr/1221169 (accessed Nov 2015).

31. Van Holle V, Deforche B, Van Cauwenberg J, et al. Relationship between the physical environment and different domains of physical activity in European adults: a systematic review. BMC Public Health 2012;12:807.

32. OOEM Task Force. Overweight and obesity evaluation and management. American Society of Bariatric Physicians, 2009. http://www.inlandempireweightloss.com/documents/ ASBPGuidelinesForOverweightAndObesityEvaluationManagement. pdf (accessed Jul 2016)

33. Marmot M, Allen J, Goldblatt $P$, et al. Fair society, healthy lives: the Marmot review: strategic review of health inequalities in England post-2010. 2008. http://www.ucl.ac.uk/whitehalll//pdf/ FairSocietyHealthyLives.pdf (accessed Aug 2013)

34. Stokols D, Allen J, Bellingham RL. The social ecology of health promotion: implications for research and practice. Am J Health Promot 1996;10:247-51.

35. Craig R, Mindell J, Hirani V. Health Survey for England 2008 , Volume 1: Physical Activity and Fitness. 2009. http://www.ic.nhs.uk/ webfiles/publications/HSE/HSE08/Volume_1_Physical_activity_and_ fitness revised.pdf (accessed Apr 2011).

36. Townsend N, Wickramasingher K, Bhatnagar P, et al. Physical Activity Statistics 2015. London: British Heart Foundation, 2015. https://www. bhf.org.uk/publications/statistics/physical-activity-statistics-2015 (accessed Jul 2016). 